\title{
Undifferentiated Retinoblastoma
}

National Cancer Institute

\section{Source}

National Cancer Institute. Undifferentiated Retinoblastoma. NCI Thesaurus. Code C66814.

A retinoblastoma composed of small, undifferentiated cells. It is often associated with necrotic changes. 